THE last number of the Royal Geographical Society of Antwerp (tome ix. $5^{\mathrm{e}}$ fascicule) contains a paper by $\mathrm{M}$. van den Gheyn on the European origin of the Aryas, a discussion of recent researches on this subject, especially of the works of Schrader, Penka, von Löher, Roth, Geiger, and Ujfalvy. The author, while regarding the subject as open to discussion, thinks that the probabilities are in favour of an Asiatic origin. Dr. Haine writes on the manners of the Californian Indians, amongst whom he passed some time about 1850. M. August Thys contributes a brief account of an early Flemish navigator, Dietrich Paesschen, who made several voyages to the Levant about I 5 I I ; and M. Baguet describes Steinen's late journey on the Xingu. An instalment of the report of the commission to study the Scheldt concludes the number.

THE expedition which the Norwegian Government dispatches this summer to the coast of Finmarken, to which we have previously referred, has for its chief object to ascertain whether there are banks or fishing grounds far from the coast, a circumstance which has never been ascertained, but which would be of great value if proved. Hitherto all fishing has been confined to the shore, but, judging from what is the case further south in Norway, such a discovery is very likely.

ON May 27 the Arctic steamer Alert sailed from Halifax with a scientific expedition for Hudson's Bay, to examine its harbours and the facilities that exist for a trade route from the Western Territory to Europe.

\section{ARTIFICIAL EARTHQUAKES}

UITE recently we noticed a paper by Prof. Milne, of Japan, which contained exhaustive records of nearly 250 earthquakes that occurred in that country in two years, and which was an earthquake history of Northern Japan during that period. We have now before us another paper from the same indefatigable investigator, also on earthquakes, but on a totally differen branch, viz. seismic experiments-in other words, on artificial earthquakes. These experiments are so original in their inception, and in some respects so unexpected in their results, that they are worth describing at some length. The paper, which was read before two successive meetings of the Seismological Society of Japan towards the close of last year, covers over eighty octavo pages, and contains several illustrations; but it will be possible to extract its principal results in a comparatively short space, There were in all ten series of experiments, carried on over three years. The object was to study phenomena connected with earth-vibrations produced either by some explosive like dynamite, or by allowing a heavy weight to fall from a height. Each set of experiments involved several weeks' preparation ; amongst the chief difficulties to be overcome were the procuring, transporting, and storing dynamite, putting the observing-stations in telegraphic connection, arranging the firing apparatus, making electric fuses, and the like, and doing all this in the midst of a populous city. These initial difficulties could never have been overcome but for the assistance of various departments of the Japanese administration, and it is pleasing to notice the help which Japanese officials freely render Prof. Milne in his interesting and important work in the field of seismic science. Nevertheless, he warns his readers at the outset that his experiments were such that it is hardly just to expect them to be carried out satisfactorily by a private inclividual ; the trouble, expense, danger, and magnitude of the arrangements which they involve make them fitter undertakings for an army corps.

The only guiding data which he had when he commenced were the results obtained by the late Mr. Robert Mallet and by Gen. Abbot. These referred only to the velocity with which earth-vibrations were propagated, and in taking diagrams of earth-motion he was therefore entering upon new ground, and therefore continually encountered new results. Sometimes it was found that the instruments employed required modification before satisfactory records could be obtained; at other times the records which were obtained gave indications of new lines of investigation, to pursue which new apparatus would be needed, and so on. Hence many of his results, he observes, can only be regarded as provisional ; for example, those which relate to the velocities of normal and transverse vibrations. The experiments were carried out, as far as circumstances would permit, in different soils, the chief agents employed being heavy weights of I 700 lbs. and upwards dropped from heights up to 40 feet, and different quantities of dynamite exploded in cavities of varying depths. The effects of these were observed with different seismographs. The observations thus made in the ten series of experiments are described with the utmost detail, illustrated by numerous plans and tables, under their appropriate heads. Prof. Milne sums up his results under a succession of heads, and the most important of them are given below. He observes, however, that in reading these conclusions it must be remembered that they only refer to experiments performed in certain kinds of ground.

Effect of Ground on Vibration.-Hills have but little effect in stopping vibrations, but excavations exert considerable influence on them. In soft, damp ground it is easy to produce vibrations of large amplitude and considerable duration; in loose, dry ground an explosion of dynamite yields a disturbance of large amplitude but of short duration, while in soft rock it is difficult to produce a disturbance the amplitude of which is sufficiently great to be recorded on an ordinary seismograph.

General Character of the Motion.-The pointer of a seismograph with a single index first moves in a normal direction, after which it is suddenly deffected, and the resulting diagram yields a figure partially dependent on the relative phases of the normal and transverse motion, which phases are in turn dependent upon the distance of the seismograph from the origin of the disturbance. A bracket seismograph indicating normal motion at a given station commences its indications before a similar seismograph arranged to write transverse motion. If the diagrams yielded by two such seismographs be compounded, they yield figures containing loops and other irregularities not unlike the figures yielded by the seismograph with the single index. Near to an origin the first movement will be in a straight line outwards from the origin ; subsequently the motion may be elliptical, like the figure 8 , and irregular. The general direction of the motion is, however, normal. Two points of ground only a few feet apart may not synchronise in their motions, and earthquake motion is probably not a simple harmonic one.

Normal Motion. - Near to an origin the first motion is outwards; at a distance from the origin the first motion may be inwards, the nature of the movement being dependent probably on the intensity of the initial disturbance and on the distance of the observing station from the origin. At a station near the origin the second or third wave is usually the largest, after which the motion dies down very rapidly in its amplitude, the motion inwards decreasing more rapidly than the motion outwards. Roughly speaking, the amplitude of normal motion is inversely as the distance from the origin. As a disturbance radiates, the period of oscillation increases, until finally it becomes equal to the period of the transverse motion. It may thus be inferred that the greater the initial disturbance the greater the frequency of the waves. A wave which appeared single at one observing station had split up into two by the time it reached the second. At stations near the origin the motion inwards is greater than the motion outwards; but at a distance the two motions are practically equal. At a station near the origin the period of the waves is at first short, but it becomes longer as the disturbance dies out. The semi-oscillations inwards are described more rapidly than those outwards.

Transverse Motion. - The laws governing the transverse motion are practically identical with those which govern the normal motion, the only difference being that in the case of normal motion they are more clearly pronounced. Near to an origin the transverse motion commences definitely but irregularly; the first two or three movements are decided, and their amplitude slightly exceeds that of those which follow, but it decreases as the disturbance radiates at a slower rate than that of the normal motion. The period increases as the disturbance radiates, and decreases as the latter begins to die out.

Relation of Normal to Transverse Motion. - Near to an origin the amplitude of normal is much greater than that of transverse motion, and as a disturbance radiates the amplitude of the latter decreases at a slower rate than that of the former, so that at a certain distance they may be equal.

Maximum Velocity and Intensity of Movements. - An earthparticle usually reaches its maximum velocity during the first inward movement, but a high velocity is sometimes attained in the first outward semi-oscillation. The value

$$
V^{2}=\frac{4}{3} g \sqrt{a^{2}+b^{2}} \times\left(\frac{\mathrm{I}-\cos \theta}{\cos ^{2} \theta}\right)
$$

used by Mallet and other seismologists to express the velocity 
of shock, as determined from the dimensions of a body which it has overturned, is a quantity not obtainable from an earthquake diagram. It represents the effect of a sudden impulse. In an earthquake a body is overturned or shattered by an acceleration, $f$, which is calculable for a body of definite dimensions. As obtained from an earthquake diagram $f$ lies between $\frac{V}{t}$ and $\frac{V^{2}}{a}$, where $V$ is the maximum velocity, $t$ is the quarter period, and $a$ is the amplitude. The initial velocity given in the formula $V^{2}=\frac{2 a^{2}}{b}$ for horizontal projection used by Mallet as identical with $V^{2}$ in the first formula, are not identical quantities. The velocity calculated from the range of projection, when projection occurs, is identical with the maximum velocity as measured directly or calculated from a diagram. The values $\frac{V^{2}}{a}$ are those used by Prof. Milne in discussing the intensity of movement. The intensity of an earthquake at first decreases rapidly as the disturbance radiates, subsequently it decreases more slowly. A curve of intensities deduced from observations at a sufficient number of stations would furnish the means of approximately calculating an absolute value for the intensity of an earthquake.

Vertical Motion.-In soft ground vertical motion appears to be a free surface-wave which advances more rapidly than the borizontal component of motion. It commences with small, rapid vibrations, and ends with vibrations which are long and slow. High velocities of transit may be obtained by the observation of this component of motion, and this is possibly an explanation of the preliminary tremors of an earthquake and the sound phenomenon.

Velocity. - The velocity 'of transit decreases as a disturbance radiates; near to an origin it varies with the intensity of the initial disturbance. In different kinds of ground, with different intensities of initial disturbance, and with different systems of observation, velocities lying between 630 feet and 200 feet per second were determined. Mr. Mallet determined a velocity in sand of 824 feet, and in granite of $\mathbf{1} 664$ feet per second. Gen. Abbot observed velocities of 8800 feet. These various determinations may all be strictly correct, the great difference between them being due partly to the nature of the rock, the intensity of the initial disturbance, and the kind of wave which was observed. In Prof. Milne's experiments the vertical free surface wave had the quickest rate of transit, the normal being next, and the transverse motion being the slowest; but the rate at which the normal motion exceeds the transverse is not constant. As the amplitude and period of the normal motion approach in value those of the transverse motion, so do the velocities of transit of these motions approach each other.

In stating the results, of which those given above are the principal, Prof. Milne refers to the particular experiments which support them, thus giving chapter and verse for his conclusions; but he thinks that if the investigations were repeated by himself or by any other investigator, although much of what he has recorded would be substantiated, more accurate results might be obtained by taking advantage of his experience. Finally he gives examples of investigations which have yet to be undertaken, and as these are valuable for others working in the same field, we append them here:-(I) An accurate determination of the rate at which the velocity of transit decreases as a disturbance radiates from its origin; (2) the relation between the velocity of transit and the intensity of the initial disturbance ; (3) the determination of the rate at which the intensity of a disturbance decreases as measured at different distances from the origin. This might perhaps lead to the construction of a curve of intensities from which the absolute intensity of the initial disturbance could be learnt ; (4) a more complete investigation of the vertical motion and of free surface waves; (5) an investigation of the inward motion of shocks. In Prof. Milne's experiments the movement of the ground from its neutral position in towards the origin of the disturbance has been performed so rapidly that he has been unable with the instruments at his disposal to measure its velocity accurately. As this is probably the most destructive element of motion, he regards its investigation as exceedingly important ; $(6)$ further investigations on the relationship between earthquake diagrams, and the overturning and projecting of various bodies ; (7) a repetition of these and of all other experiments, on different kinds of ground.

\section{THE INFLUENCE OF FORESTS ON CLIMATE}

THE third number of Petermann's Mittheilungen for this year contains an article by Herr $\mathrm{A}$. Woeikof on the influence of forests on climate. The commencement of a scientific investigation of this subject was made when the Bavarian forest meteorological stations were established, and when Prussia, Alsace-Lorraine, France, Switzerland, and Italy followed the example. As a general rule it may be laid down that in the warm seasons, as between forests and places close at hand which are treeless (I) the temperatures of the earth and air are lower in the former, (2) their variations are less, (3) the relative humidity is greater. After examining observations as to evapora. tions, Herr Woeik of states that the influence of forests in diminishing evaporation from water and the soil is so great that it cannot be accounted for alone by the lower temperature of the hot months, the greater humidity, or even by the shade. An important influence, which has hitherto been but little appreciated, is the protection from the wind afforded by the trees, and this the writer regards as more important than all the others together in reducing the degree of evaporation. With regard to the influence of forests on rain and snowfall, there is as yet only a single series of observations supplying comparative statistics, and extending over a sufficiently long period. These were taken in the neighbourhood of Nancy, and they show an important influence of forests in increasing the rainfall. It might appear that the effect of forests on rain in the climate of Central Europe in winter would be small, for the difference between the temperature and humidity of the forest and the open is very little, and the quantity of moisture in the atmosphere is small. But the observations show that it is at this time of the year that forests get much more rain. This the writer attributes to the clouds being lower, the resistance which the forest offers to the movement of the air, and to the moist west wind. Forests retain rain by the undergrowths of grass, moss, \&c., much better than open ground, and let water off superficially only after a heavy rainfall; the remainder filters upwards slowly, and much of it is used for the evaporation of the trees. Although forests, especially thick, luxuriant forests, cannot exist without certain supplies of moisture, yet it is the same to them when the supplies come, for they retain what they get and use it over a long period. One example of this is the Lenkoran forest on the west coast of the Caspian, where the vegetation is more luxuriant than in any other part of Europe, yet very little rain falls in summer, but the rainfall in autumn and winter is great. The water is stored up by the forest, and is used in evaporation during the heat of summer. Humidity of the atmosphere, however, is not inconsistent with a high temperature, as the Red Sea shows; but in forests the humidity is due to the evaporation of the leaves-in other words, to a process by which heat is converted into work, and hence the coolness. Herr Woeik of then endeavours to ascertain the influence of forests on the climatic conditions of their neighbourhoods in the western parts of the. Old World, between the 38 th and 52nd degrees N. latitude, the places selected being in all cases in the open. Thus for the 52nd degree eight stations are taken between Valentia in Ireland on the west and the Kirghiz steppes on the east; for the 5oth, Guernsey on the west, Semipalatinsk on the east, and thirteen stations, and so on for each two degrees of latitude to $38^{\circ}$. The general result of the observations in fifty-stations in six different degrees of latitude is that in Western Europe and Asia large forests have a great influence on the temperature of places near them, and that by their influence the normal increase of temperature as we travel eastward from the Atlantic Ocean to the interior of the continent is not merely interrupted, but they give places far removed from the coast a cooler summer than those actually on the sea. A striking example of this is Bosnia. An examination of the statistics shows (I) that in Bosnia the summer is $2^{\circ} \cdot 5$ to $4^{\circ} \cdot 5$ cooler than in Herzegovina ; (2) even on the island of Lissa, in the full influence of the Adriatic Sea, the summer temperature is more than a degree higher than that of Bosnia, which is separated by lofty mountain ranges from the sea. Bosnia owes this comparatively cool summer to its great forests, while Herzegovina is almost disafforested. To sum up: forests exercise an influence on climate which does not cease on their borders, but extends over a larger or smaller adjacent region according to the size, kind, and position of forest. Hence man by afforestation and disafforestation can modify the climate around him; but it is an extreme position to hold that by afforestation the waste places 